\title{
Ressecção de cisto e abscesso renais por laparoscopia em um cão
}

\author{
[Resection of renal cyst and abscess by laparoscopy in a dog] \\ S.T.L. Pinto Filho ${ }^{1}$, M.V. Brun ${ }^{2}$, F. Dalmolin ${ }^{1}$, H. Hartmann ${ }^{3}$, D.T. Pereira ${ }^{3}$, V.H. Pohl ${ }^{1}$, \\ A.S. Coutinho Jr. ${ }^{1}$, C.F. Giglio ${ }^{3}$, F.S. Wiecheteck ${ }^{1}$, M.T. Oliveira ${ }^{1}$, \\ C.L.B. Godoy ${ }^{2}$, A.M. Hora ${ }^{3}$ \\ ${ }^{1}$ Aluno de pós-graduação - Universidade Federal de Santa Maria (UFSM) - Santa Maria, RS \\ ${ }^{2}$ Universidade Federal de Santa Maria (UFSM) - Santa Maria, RS \\ ${ }^{3}$ Médica veterinária - Residente do Hospital Veterinário - UFSM - Santa Maria, RS
}

\section{RESUMO}

Cistos renais podem formar-se em qualquer parte do néfron e dos ductos coletores. Alguns são hereditários, originando-se durante a organogênese, e outros se desenvolvem no tecido renal normal, depois que os rins estão completamente formados. No presente relato, descreve-se a ressecção de cisto e abscesso renais, por cirurgia laparoscópica em um cão. Para o acesso, foram utilizados três portais, dois de $10 \mathrm{~mm}$ de diâmetro e um de $5 \mathrm{~mm}$, dispostos na parede abdominal lateral direita e, num segundo momento, na parede abdominal lateral esquerda. Conclui-se, portanto, que a técnica laparoscópica com três portais permite a realização de ressecção de cisto e abscesso renais em cães, sem a ocorrência de recidivas em curto prazo.

Palavras-chave: cirurgia, videolaparoscopia, cão, rim

\begin{abstract}
Renal cysts can be formed anywhere in the nephron and collecting duct system. Some are hereditary, originated during organogenesis, and others could have origin in the normal kidney tissue, after the kidney's development. This report describes the resection of renal cysts and abscesses by laparoscopic surgery in a dog. In order to access the cavity, three portals were used; two with 10mm and another with $5 \mathrm{~mm}$ diameter, in the right lateral abdominal wall, and in another moment, in the left lateral abdominal wall. It is concluded that the laparoscopic technique with three portals allows the resection of renal cysts and abscesses in dogs, without the occurrence of relapses in the short postoperative time.
\end{abstract}

Keywords: surgery, laparoscopy, dog, kidney

\section{INTRODUÇÃO}

Doenças perirrenais em pequenos animais são relativamente incomuns. Entre elas, os pseudocistos perirrenais são caracterizados como acúmulo de variadas quantidades de fluido, dentro de sacos fibrosos e em volta de um ou ambos os rins, estando frequentemente fixos ao hilo ou aos polos renais. O termo pseudocisto é utilizado para essa afecção pelo fato de ela não possuir camada epitelial, enquanto os cistos renais a possuem. Cistos renais são de origem

Recebido em 9 de agosto de 2012

Aceito em 8 de maio de 2013

*Autor para correspondência (corresponding author)

E-mail: mauriciovelosobrun@hotmail.com tubular, podendo envolver a cápsula glomerular ou qualquer porção dos túbulos renais. Já os pseudocistos ocorrem externamente ao parênquima renal, entre o parênquima e a cápsula renal, ou entre o parênquima renal e o retroperitônio (Ferreira, 2008).

Cistos podem formar-se em qualquer parte do néfron e do sistema dos ductos coletores. Algumas lesões císticas são hereditárias, originando-se durante a organogênese. Outros cistos desenvolvem-se no tecido renal normal, depois que os rins estão completamente 
formados. Eles podem ser grandes e em pequeno número ou múltiplos e pequenos (Christie e Bjorling, 2007). Segundo Mckenna e Capenter (1980), cistos renais congênitos, múltiplos ou solitários, envolvendo um ou ambos os rins, têm sido relatados em cães, porcos, ratos, coelhos, gatos e outras espécies.

Os sinais associados aos cistos renais são distensão abdominal em decorrência do aumento de volume renal, ou depressão, anorexia, emese, polidipsia, poliúria e perda de peso em decorrência de insuficiência renal. Grandes cistos, isolados ou múltiplos, podem ser identificados no parênquima renal por meio de urografia excretora ou de ultrassonografia. A moléstia policística pode ser unilateral, e a remoção do rim afetado pode ser aconselhada em decorrência de sua predisposição a infecção (Christie e Bjorling, 2007). Beck et al. (2000) e Pigatto et al. (2011) consideram que dor persistente, infecção, hematúria recorrente e compressão do sistema coletor renal ou de órgãos adjacentes são indicações para o tratamento de cistos renais simples ou no contexto de doença renal policística.

Cães e gatos com doenças renais apresentam, na maioria das vezes, características ultrassonográficas dos rins semelhantes, sendo necessária a de exames complementares para determinação do diagnóstico diferencial. Cistos renais podem aparecer isolados ou múltiplos, tendo por características ultrassonográficas contorno circular fino e regular, com conteúdo anecoico e formação de reforço acústico posterior. Os cistos podem deformar o contorno renal caso sejam grandes ou se uma doença renal policística estiver presente. Urinálise e testes de função renal são exames laboratoriais importantes a serem analisados, pois são capazes de fornecer informações sobre lesão e função renais. A biopsia renal é a técnica de eleição para o diagnóstico de doenças renais, pois possibilita o estabelecimento de diagnóstico definitivo e determina a severidade da lesão (Silva et al., 2008).

As opções terapêuticas consistem em aspiração do conteúdo do cisto, marsupialização percutânea, ressecção cirúrgica pelo acesso convencional e, mais recentemente, por cirurgia laparoscópica. Outra solução apontada corresponde à ressecção parcial da cápsula com ou sem omentalização, dependendo da natureza do líquido (Pigatto et al., 2011).

Atualmente, procedimentos minimamente invasivos são rotineiramente utilizados em medicina com o objetivo de diminuir alguns inconvenientes relacionados à cirurgia convencional. Entre estes procedimentos, encontra-se a cirurgia laparoscópica. Estudos demonstram sua superioridade em relação à dor pós-operatória, às complicações trans e pósoperatórias, à aparência estética, aos custos hospitalares, à recuperação pós-operatória e ao período de hospitalização. A realização de cirurgias laparoscópicas em rins de cães tem sido principalmente descrita na medicina, na qual estes animais são utilizados como modelos experimentais. Em veterinária, poucos estudos descrevem o emprego da cirurgia laparoscópica em casos clínicos envolvendo o referido órgão.

O objetivo do presente trabalho foi relatar um caso de ressecção de cisto e abscesso renais em ambos os rins, por intervenção laparoscópica com três portais, em um canino sem raça definida.

\section{CASUÍSTICA}

Foi atendido no hospital veterinário universitário da UFSM um canino, macho, sem raça definida, aproximadamente 10 anos de idade, o qual servia como doador de sangue do estabelecimento. O animal estava sendo utilizado em uma aula prática de ultrassonografia abdominal, na disciplina de Diagnóstico por Imagem, quando foram observadas deformações no contorno de ambos os rins. $\mathrm{O}$ esquerdo apresentava área ecogênica, com aspecto de celularidade intensa, contorno regular, medindo, aproximadamente, $6,3 \mathrm{~cm} \times 4,6 \mathrm{~cm}$, que abrangia desde o meio do rim até o polo caudal, não sendo observado resquício da arquitetura do órgão na referida região. Observaram-se, ainda, mais duas áreas de contornos regulares, conteúdo anecoico, sugestivas de cistos, localizadas na cortical do mesmo rim (Fig. 1A).

Já o rim direito apresentava área circunscrita, a qual se projetava dorsocranialmente, a partir do polo cranial, medindo, aproximadamente, $4,8 \mathrm{~cm}$ $\mathrm{x} 4,3 \mathrm{~cm}$, com conteúdo hipoecoico, contorno ligeiramente irregular, à custa de estruturas 
ecogênicas provenientes ou aderidas à parede (Fig. 1B).

O animal foi submetido a coleta de sangue duas vezes, num intervalo de seis dias, para realização de hemograma e bioquímica sérica (albumina, ALT, creatinina, fosfatase alcalina, ureia $\mathrm{e}$ proteínas totais). As alterações encontradas nas duas baterias de exames foram diminuição do número de plaquetas $(123.000 / \mu \mathrm{L})$, com presença de aglomerados plaquetários, e aumento da ALT (220UI/L) e FA (183,98UI/L). Então, optou-se pelo encaminhamento do animal para procedimento cirúrgico laparoscópico, objetivando o diagnóstico definitivo e o tratamento das alterações renais.

Após jejum de 12 horas, a medicação pré-anestésica do cão foi realizada com maleato de midazolam (Cristália - Produtos Químicos Farmacêuticos Ltda., Itapira-SP, Brasil) $(0,5 \mathrm{mg} / \mathrm{kg})$ e sulfato de morfina (Cristália Produtos Químicos Farmacêuticos Ltda., ItapiraSP, Brasil) $(0,5 \mathrm{mg} / \mathrm{kg})$, IM, seguindo-se pela canulação venosa com cateter $22 \mathrm{G}$ e instalação de fluidoterapia com ringer lactato a $10 \mathrm{~mL} / \mathrm{kg} / \mathrm{h}$. A indução anestésica foi realizada com propofol $(4 \mathrm{mg} / \mathrm{kg}), \mathrm{IV}$, e a manutenção com isoflurano (Cristália - Produtos Químicos Farmacêuticos Ltda., Itapira-SP, Brasil) vaporizado em oxigênio a $100 \%$. A analgesia foi alcançada por meio da aplicação epidural de associação com cloridrato de lidocaína $2 \%$ sem vasoconstritor $(2 \mathrm{mg} / \mathrm{kg})$, cloridrato de bupivacaína $2 \%$ sem vasoconstritor $(2 \mathrm{mg} / \mathrm{kg})$ e sulfato de morfina $(0,1 \mathrm{mg} / \mathrm{kg})$. A quimioprofilaxia antimicrobiana foi realizada com cefalotina sódica (30mg/kg), IV, 30 minutos antes do início da cirurgia.

Com o paciente em decúbito dorsal e após tricotomia abdominal ampla, realizou-se antissepsia com álcool-iodo-álcool e colocação dos panos de campo estéreis. Procedeu-se à incisão de pele na parede abdominal lateral direita, de aproximadamente $1 \mathrm{~cm}$, na altura da prega inguinal, por meio do qual foi introduzida uma cânula de $10 \mathrm{~mm}$ de diâmetro pela técnica aberta. A cavidade foi insuflada com $\mathrm{CO}_{2}$ até a pressão de $12 \mathrm{mmHg}$, sendo, em seguida, introduzidos dois trocartes adicionais lateralmente à esquerda (10mm de diâmetro) e à direita ( $5 \mathrm{~mm}$ de diâmetro) no flanco, mantendose disposição triangular entre os portais. A laparoscopia teve início com a introdução transparietal da agulha de Verres e posterior aspiração do cisto do rim esquerdo, sendo retirados $103 \mathrm{~mL}$ de líquido com coloração escura (achocolatado ou Coca-cola). Na sequência, iniciaram-se a dissecção e a remoção da cápsula do cisto com pinça de apreensão e tesoura, sendo fixado o omento no local do cisto com aplicação de quatro clipes de titânio, tamanho médio, por meio de clipador laparoscópico.

Durante o procedimento, foi evidenciada massa com aparência tumoral no polo cranial do rim esquerdo, optando-se pela coleta de fragmento renal com pinça de biopsia. Após a coleta do fragmento, foi realizada lavagem exaustiva da cavidade abdominal com solução de $\mathrm{NaCl}$ 0,9\% e posterior drenagem com aspirador cirúrgico. Ao final, foram retirados os portais (cânula e trocartes) e suturados a parede muscular e o tecido subcutâneo com ácido poliglicólico 2-0 com pontos Sultan. A dermorrafia foi realizada com náilon 3-0 e pontos isolados simples. Por questões operacionais, optou-se pela intervenção apenas do rim esquerdo.

No pós-operatório, foram administrados cloridrato de tramadol $(4 \mathrm{mg} / \mathrm{kg})$ a cada 12 horas, durante dois dias, e meloxicam $(0,2 \mathrm{mg} / \mathrm{kg})$ a cada 24 horas, durante três dias, ambos por via IM.

O líquido cístico foi encaminhado para análise, a qual revelou $\mathrm{pH} 5,0$; proteínas $2,6 \mathrm{~g} / \mathrm{dL}$; sangue oculto ++++; creatinina $1,25 \mathrm{mg} / \mathrm{dL}$; densidade de 1014, bem como células com intenso grau de degeneração e grande quantidade de hemácias. Também foi encaminhada amostra do líquido para cultura e antibiograma, mas não se observou crescimento bacteriano. A cápsula foi encaminhada para biopsia, a qual revelou ser nefroesclerose multifocal com formação de cistos de retenção urinária. A biopsia do fragmento renal demonstrou a presença de pólipo fibroepitelial.

Vinte e um dias após a intervenção no rim esquerdo, foi realizada nova avaliação ultrassonográfica, observando-se área hipoecogênica com algumas linhas ecogênicas, imagem que sugeria discreto volume de líquido delimitado pelo omento. A imagem media, aproximadamente, 4,2 cm x 2,9cm (Fig. 1C). Neste mesmo dia, foi realizado novo procedimento para correção do mesmo problema 
no rim contralateral. Para tal, foram repetidos os exames laboratoriais supracitados a fim de se verificarem as condições do animal para realização da cirurgia. Como alteração, as plaquetas estavam em número reduzido $(146.000 / \mu \mathrm{L})$, com presença de aglomerados plaquetários, e a ALT estava aumentada $(174,4 \mathrm{UI} / \mathrm{L})$. O procedimento cirúrgico foi realizado da mesma forma que o anteriormente citado (Fig. 1D e 1E), com disposição triangular dos portais, aspiração do líquido cístico $(68 \mathrm{~mL})$ com agulha de Verres, divulsão e remoção da cápsula renal, fixação do omento no local do cisto (Fig. 1F) e lavagem da cavidade com ringer lactato. Oportunamente, realizou-se biopsia hepática em razão dos valores séricos das enzimas hepáticas, os quais estavam cronicamente acima dos normais para a espécie. As suturas da parede muscular, do espaço subcutâneo e da pele foram as mesmas da primeira intervenção cirúrgica.

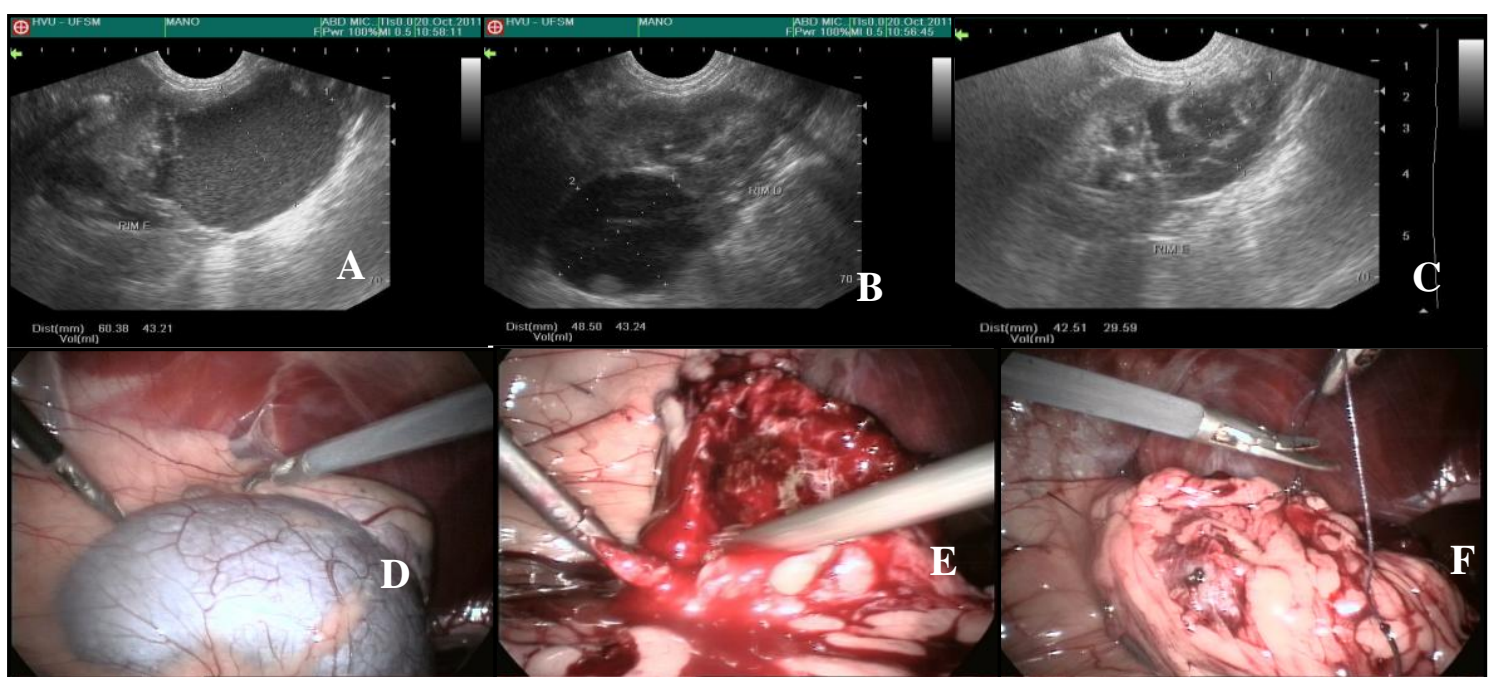

Figura 1. Cão. Imagens ultrassonográficas dos rins. (A) Pré-operatório do rim esquerdo. Observar área

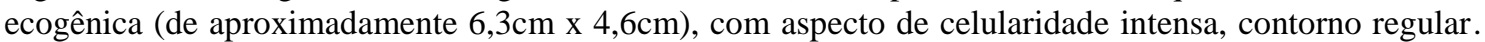
(B) Pré-operatório do rim direito. Observar área circunscrita (de aproximadamente $4,8 \mathrm{~cm} \times 4,3 \mathrm{~cm}$ ) $\mathrm{se}$ projetando dorsocranialmente, a partir do polo cranial, com conteúdo hipoecoico e contorno ligeiramente irregular. (C) Pós-operatório do rim esquerdo 21 dias após a cirurgia. Observa-se área hipoecogênica com algumas linhas ecogênicas (de aproximadamente $4,2 \mathrm{~cm} \times 2,9 \mathrm{~cm}$ ), imagem que sugeria discreto volume de líquido delimitado pelo omento. (D) Visualização laparoscópica do rim direito evidenciando-se a projeção dos dois abscessos (setas). (E) Cavitação renal formada pelo abscesso de maior diâmetro após a ressecção parcial de sua cápsula. Observa-se a cânula de aspiração promovendo irrigação e drenagem da cavidade cística. (F) Omentalização do rim direito obtida a partir de pontos interrompidos simples pela técnica intracorpórea.

Como realizado na cirurgia anterior, também se encaminhou amostra do líquido para cultura e antibiograma, demonstrando crescimento bacteriano de Escherichia coli, sensível à maioria dos antibióticos testados. Foi, então, comprovado o diagnóstico de abscesso renal direito, sendo que a biopsia hepática demonstrou fibrose periportal difusa leve e colestase multifocal leve.

Após os procedimentos, o cão foi doado e encontrava-se em bom estado de saúde 27 meses após a segunda operação. Alimentava-se com ração comercial da linha terapêutica para pacientes nefropatas.

\section{DISCUSSÃO}

No presente relato, não foi possível chegar a uma conclusão sobre a real causa dos cistos renais, pois inexistia histórico clínico prévio. Optou-se pela ressecção do cisto por videolaparoscopia considerando que o acesso pode promover menor lesão tecidual (Pigatto et al., 2011) e permitir o diagnóstico e o tratamento durante única sessão.Segundo o conhecimento dos autores, a 
terapêutica de abscesso renal em cães pela técnica descrita ainda não havia sido relatada.

Alguns cistos se formam no tecido renal durante o desenvolvimento fetal, enquanto outros depois que os rins estão completamente formados, podendo ser grandes e em pequeno número ou múltiplos e pequenos (Christie e Bjorling, 2007). No caso em questão, o exame ultrassonográfico revelou várias estruturas císticas de diferentes tamanhos, afetando diferenciadas áreas dos dois órgãos. Segundo Mckenna e Capenter (1980), cistos renais congênitos, múltiplos ou solitários, envolvendo um ou ambos os rins, têm sido relatados em cães, porcos, coelhos, ratos, gatos e outras espécies.

Os animais afetados podem apresentar sinais clínicos decorrentes de insuficiência renal (Christie e Bjorling, 2007), dor persistente, infecção e hematúria recorrente (Pigatto et al., 2011). No caso descrito, o canino era utilizado como doador de sangue do hospital e nunca havia apresentado nenhum desses sinais.

O diagnóstico presuntivo de cisto renal foi realizado por meio de ultrassonografia abdominal, a qual revelou, no rim esquerdo, área ecogênica com aspecto de celularidade intensa, contorno regular, que abrangia desde o meio do rim até o polo caudal, não sendo observado resquício da arquitetura do órgão na referida região. Observaram-se, ainda, mais duas áreas de contornos regulares e conteúdo anecoico, localizadas na cortical. $\mathrm{O}$ rim direito apresentava área circunscrita, a qual se projetava dorsocranialmente, a partir do polo cranial, com conteúdo hipoecoico, contorno ligeiramente irregular, à custa de estruturas ecogênicas provenientes ou aderidas à parede. Segundo Silva et al. (2008), cistos renais podem aparecer isolados ou múltiplos, tendo por características ultrassonográficas contorno circular fino e regular, com conteúdo anecoico. No presente relato, o aumento de volume localizado no rim direito apresentava conteúdo hipoecoico, que, após analisado, demonstrou crescimento bacteriano, o qual, segundo a cultura, revelou-se Escherichia coli. Porém, macroscopicamente, o conteúdo era similar ao do rim esquerdo, advogando quanto à necessidade de se realizar sempre o antibiograma do líquido cístico (Paulo et al., 2005). O resultado do referido exame demonstrou que a quimioprofilaxia antimicrobiana escolhida estava apropriada. Como os exames físicos e complementares préoperatórios não demonstraram sinais de infecção sistêmica, administrou-se o antibiótico pelo período de sete dias, sem associações complementares.

Os cistos podem deformar o contorno renal se forem grandes ou se uma doença renal policística estiver presente, e devem ser diferenciados de hematomas, abscessos e tumores. Essas afecções demonstram paredes espessas, irregulares, conteúdo que não se apresenta completamente anecoico, podendo possuir septações internas (Silva et al., 2008). No caso em questão, após verificação de crescimento bacteriano no conteúdo do aumento de volume, ligeiramente irregular, no rim direito, obteve-se diagnóstico de abscesso renal, diferindo do esquerdo, o qual apresentava aumento de volume sem a presença de microrganismos, confirmando, portanto, o diagnóstico de cisto. Mesmo sem possuírem o diagnóstico preciso entre abcesso e cisto em ambas as condições, os autores optaram pela omentalização da superfície cística a fim de se reduzir a chance de recidiva e de se melhorar a condição cicatricial, uma vez que o omento melhora a irrigação, o aporte de células de defesa, a drenagem linfática, além de reduzir o espaço morto (Hosgood, 1990) e providenciar células-tronco para a superfície lesionada. Fugiwara et al. (2003) citaram que essa drenagem é favorecida pela enorme capilaridade do omento e que, portanto, possui excelente capacidade de absorção, podendo ter, inclusive, significado clínico em condições em que haja grande quantidade de fluido.

A cirurgia laparoscópica constitui a opção terapêutica recentemente utilizada para pacientes com cistos renais (Pigatto et al., 2011). No presente caso, optou-se pela utilização dessa modalidade, tendo em vista que ela causa menos trauma cirúrgico, apresenta recuperação pósoperatória mais rápida e com menor dor (Brun e Beck, 1999). Foi permitida, neste caso, a realização de todas as manobras cirúrgicas necessárias para a correção da alteração, como aspiração do líquido, ressecção das cápsulas e omentalização dos locais em que se encontravam os cistos, com boa visualização renal e da cavidade como um todo. Verificou-se ainda recuperação pós-operatória satisfatória, sem a presença de dor decorrente do pneumoperitônio, 
e retorno à alimentação 12 horas após a cirurgia, não havendo necessidade de analgesia resgate após o período de tratamento com o antiinflamatório e o analgésico opioide.

\section{REFERÊNCIAS}

BECK, J.A.; BELLENGER, C.R.; LAMB, W.A. et al. Perirenal pseudocysts in 26 cats. Aust. Vet. J., v.3, p.166-171, 2000.

BRUN, M.V.; BECK, C.A.C. Aplicações clínicas e experimentais da laparoscopia em cães - artigo de revisão. Rev. FZVA, v.5/6, p.123-135, 1999.

CHRISTIE, B.A.; BJORLING, D.E. Rins. In: SLATTER, D. Manual de cirurgia de pequenos animais. 3.ed. São Paulo: Manole, 2007. p.16061619.

FERREIRA, A.R.A. Pseudocisto perirenal bilateral em um gato doméstico de pêlo curto: revisão de literatura e relato de caso. 2008. 58f. Monografia (Graduação em Medicina Veterinária), Universidade Federal da Bahia.
FUJIWARA, K.; KIGAWA, J.; RASEGAWA, K. et al. Effect of simple omentoplasty and complications after pelvic lymphadenectomy. Int. J. Gynecol. Cancer, v.13, p.61-66, 2003.

HOSGOOD, G. The omentum - The forgotten organ: physiology and potential surgical applications in dogs and cats. Comp. Cont. Educ. Pract., v.12, p.45-50, 1990.

MCKENNA, S.C; CAPENTER, J.L. Polycystic disease of the kidney and liver in the Cairn terrier. Vet. Pathol., v.17, p.436-442, 1980.

PAULO, N.M; MENDES, D.L.; DE BRITO, M.S. et al. Drenagem percutânea de cisto paraprostático, guiada por ultra-som em um cão. Acta Sci. Vet., v.33, p.325-328, 2005.

PIGATTO, J.; FERANTI, J.P.S.; PHOL, V.H. et al. Cistolitectomia e ressecção de cisto renal por laparoscopia em uma cadela com aderências intraperitoneais: relato de caso. Arq. Bras. Med. Vet. Zootec., v.63, p.858-865, 2011.

SILVA, V.C.; MAMPRIM, M.J.; VULCANO, L.C. Ultra-sonografia no diagnóstico das doenças renais em pequenos animais. Vet. Zoot., v.15, p.435-444, 2008. 